\title{
EFFECT OF OPERATING PARAMETERS OF HYDRAULIC FRACTURING TECHNOLOGY AND RESERVOIR POROSITY ON FRACTURE GEOMETRY
}

\author{
Nguyen Huu Truong \\ PetroVietnam University, Vietnam \\ E-mail: truongnh@pvu.edu.vn
}

Received: 29-9-2016

\begin{abstract}
In the past decades, a large amount of oil production in the Cuu Long Basin was mainly exploited from the basement reservoir and one part from oil production in the Miocene sandstone reservoir, and a small amount of oil production from the sandstone Oligocene reservoir. Many discovery wells and production wells in lower Oligocene sandstone had high potential of oil and gas production reserves in which the average reservoir porosity was from $10 \%$ to $18 \%$, and reservoir permeability was in the range of $0.1 \mathrm{md}$ to $5 \mathrm{md}$. Due to high reservoir heterogeneity, complicated geological structure in high closure pressure up to 7,700 psi, the problem in the Oligocene reservoir is very poor fracture conductivity among the fractures with the upper seal and lower seal by shale. The big challenging deal with this problem is to stimulate the reservoir by hydraulic fracturing to enhance oil and gas production which is required to the study. In this article, the author has presented the effects of operating parameters of hydraulic fracturing as injection time, injection rate, leak-off coefficient, and reservoir porosity based on the 2D PKN-C fracture geometry accounting for leak-off coefficient, spurt loss in terms of power law parameters on economic performance by design of experiment (DOE) and apply a tool of response surface method with the recommended ranges of operating parameter in the field experience. In the recent years, through the successful application of hydraulic fracturing to stimulate reservoirs for well completion in Oligocene reservoir, that technique has widely been used in the field for improving oil production.
\end{abstract}

Key words: Operating parameters of hydraulic fracturing, the 2D PKN-C fracture geometry, economic performance, operating parameters, reservoir parameter.

\section{OLIGOCENE RESERVOIR DESCRIPTION}

The energy demand of oil and gas is rapidly increased worldwide and the energy supply for developing the domestic economy is necessary particularly. Therefore, to increase oil production rate by tertiary method, the hydraulic fracturing stimulation is widely used in the petroleum industry for enhancing oil production to apply the vertical well, multistage hydraulic fracturing in horizontal well. In Vietnam, oil production rate in the Oligocene reservoir was declined in a long time due to many reasons such as the decline in pressure of reservoir, the low reservoir permeability from $0.1 \mathrm{md}$ to $5 \mathrm{md}$, and low reservoir porosity from $10 \%$ to $18 \%$, heterogeneity, and complexity of the reservoir. These problems lead to poor conductivity among the fractures. To deal with this problem, it is necessary to stimulate the reservoir of hydraulic fracturing stimulation. In the Cuu Long basin, there are three pay zones of oil production that consist of the basement reservoir, Miocene sandstone 
reservoir, and the Oligocene sandstone reservoir. In the previous report, the amount of oil production reserves which can be exploited from the basin has been estimated at about 5,600 million to 5,950 million barrels of oil equivalent. That is equal to potential hydrocarbon reserves of about 22.4 billion to 23.8 billion of oil equivalents. In which, $70 \%$ of oil production is exploited in the fracture basement reservoir, whereas $18 \%$ of oil production in the Oligocene reservoir $(1,033$ million barrels of oil reserves) and $12 \%$ of oil production in the Miocene reservoir, respectively. On the other hand, total amount of oil production in Oligocene reservoir in the White Tiger oil field is only 76.7 million barrels of oil which is equal to $4.6 \%$ of total amount of oil production in the White Tiger and $7.4 \%$ of oil in the Oligocene reservoir. These layers in the Oligocene reservoir include Tra Tan of Oligocene C, Oligocene D and Oligocene E, Tra $\mathrm{Cu}$ in the Oligocene F. In this article, the author has mentioned in the Oligocene E reservoir and has presented the effects of operating parameters of hydraulic fracturing and reservoir porosity on economic performance in the Oligocene reservoir. The result of the research is very useful in order to select good operating parameters of hydraulic fracturing in the Oligocene. In the future work, the author will present the combined operating parameters of hydraulic fracturing and the other parameters that cannot be controlled such as reservoir permeability, fracture height, reservoir porosity effect on the economic performance.

\section{FRACTURING FLUID SELECTION AND FLUID MODEL}

In 1991, Economides et al., presented fracturing fluid selection guide for petroleum industry practices. Ideally, the fracturing fluid is compatible with the formation rock properties; also it is compatible with fluid flow in the reservoir, reservoir pressure and reservoir temperature. Fracturing fluid that generates pressure in order to transport proppant slurry and open fracture, produce fracture growth during pumping, also fracturing fluid should minimize pressure drop alongside and inside the pipe system in order to increase pump horsepower with the aim of increasing a net fracture pressure to produce more fracture propagation. In fracturing fluid system, the breaker additive would be added to the fluid system to clean up the fractures after treatment. Due to high temperature of Oligocene $E$ reservoir up to $266^{\circ} \mathrm{F}$, Borate- crosslinked 30 pptg HPG with persulfate with 8 pptg $\mathrm{Na}_{2} \mathrm{~S}_{2} \mathrm{O}_{8}$ has been selected for fracturing fluid system. To predict precisely the fracture geometry as fracture half-length, fracture width during pumping, the power law fluid model would be applied in this study. Then the most fracturing fluid model is usually given by:

$$
\tau=K \gamma^{n}
$$

Where: $\tau$ - shear stress, $\gamma$ - shear rate, $K$ consistency coefficient, $n$ - rheological index as flow behavior index that is non-dimensional but related to the viscosity of the nonNewtonian fracturing fluid model [1].

The power law model can be expressed by:

$$
\log \tau=\log K+\mathrm{n} \log \gamma
$$

Slope $=\left[\left(N \sum X Y\right)-\left(\sum X \sum Y\right)\right] /\left[\left(N \sum X^{2}\right)-\left(\sum X\right)^{2}\right]$

$$
\text { Intercept }=\left(\sum Y-n \sum X\right) / N
$$

Where $X=\log \gamma, Y=\log \tau$, and $N=$ Data number. Thus $n=$ Slope and $K=\operatorname{Exp}$ (Intercept).

\section{PROPPANT SELECTION}

In order to select proppant, the proppant would be selected correctly as proppant type, proppant size, proppant porosity, proppant permeability and proppant conductivity, strength proppant under effective stress pressure of the reservoir. In order to evaluate precisely the fracture conductivity of the fractures account for proppant damage factor, of course proppant is used to open fractures and keep the fractures open for a long time in high fracture conductivity while pump pressure is shut down and fracture begins to close due to effective stress and overburden pressure. Ideally, proppant selection needs to be enough proppant strength to resist the crush, erosion, and corrosion in the well. Due to closure pressure of Oligocene reservoir up to 7,700 psi, 


\section{Effect of operating parameters of hydraulic...}

proppant type that should be selected is the intermediate strength proppant (ISP) as Carbo Lite Ceramics proppant with proppant size of 20/40, (Nolte and Economides) which is good at fracturing fluid as presented in the fluid selection.

Table 1. Proppant selection at optimal parameters

\begin{tabular}{lcc}
\hline \multicolumn{1}{c}{ Parameter } & Value \\
\hline Proppant type & $20 / 40$ CARBO-Lite \\
Specific gravity & 2.71 \\
Strength & Intermediate \\
Diameter & 0.0287 in \\
Packed porosity & 0.35 \\
Conductivity at 7,700 psi closure & $3,400 \mathrm{md}-\mathrm{ft}$. \\
pressure (at 1.78 ${\left.\mathrm{lb} / \mathrm{ft}^{2}\right)}^{\text {Conductivity damage factor }}$ & 0.6 \\
Closure pressure & $7,700 \mathrm{psi}$ \\
\hline
\end{tabular}

\section{FRACTURE GEOMETRY MODEL}

In this study, the 2D PKN fracture geometry model (Two dimension PKN; Perkins and Kern, 1961; Nordgren, 1972) in fig. 1 is used to present the significant fracture geometry of hydraulic fracturing stimulation for low permeability, low porosity and poor conductivity as Oligocene E reservoir, which requires the fracture half-length of fracture design and evaluates the fracture geometry. After incorporation of carter solution II, the model known as 2D PKN-C (Howard and Fast, 1957) has incorporated the leak-off coefficient, in terms of consistency index $(K)$, flow behavior index $(n)$, injection rate, injection time, fluid viscosity, fracture height. The model detail in (Valko's and Economides, 1995) is shown in table 2 [2].

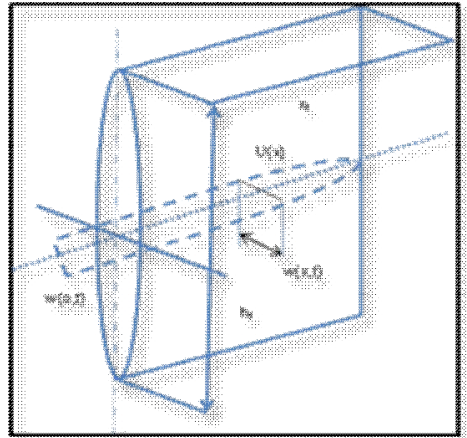

Fig. 1. The 2D PKN-C fracture geometry model

Table 2. Reservoir data of $X$ well in Oligocene E reservoir, offshore Vietnam

\begin{tabular}{|c|c|}
\hline Parameter & Value \\
\hline Target fracturing depth, ft. & 12,286 \\
\hline Reservoir drainage area, acres & 122 \\
\hline Reservoir drainage radius, ft. & 1,300 \\
\hline Wellbore radius, ft. & 0.328 \\
\hline Reservoir height, ft. & 72 \\
\hline Reservoir porosity, \% & $10 \%$ to $18 \%$ \\
\hline Reservoir permeability, md & 0.5 \\
\hline Reservoir fluid viscosity, $\mathrm{cp}$ & 1.5 \\
\hline Oil formation volume factor, RB/STB & 1.4 \\
\hline Total compressibility, $\mathrm{psi}^{-1}$ & $1.00 \times 10^{-5}$ \\
\hline Young's modulus, psi & $5 \times 10^{6}$ \\
\hline Sandstone Poisson's ratio & 0.25 \\
\hline Initial reservoir pressure, psi & 4,990 \\
\hline Reservoir temperature, ${ }^{\circ} \mathrm{F}$ & 266 \\
\hline Oil API & 36.7 \\
\hline Gas specific gravity & 0.79 \\
\hline Bubble point pressure, psi & 1,310 \\
\hline Flowing bottom hole pressure, psi & 3,500 \\
\hline Closure pressure, psi & 7,700 \\
\hline
\end{tabular}

The maximum fracture width in terms of the power law fluid parameters is given by:

$$
w_{f}=9.15^{\frac{1}{2 n+2}} \times 3.98^{\frac{n}{2 n+2}}\left(\frac{1+(\pi-1) n}{n}\right)^{\frac{n}{2 n+2}} K^{\frac{1}{2 n+2}} \times\left(\frac{\left(q_{i} / 2\right)^{n} h_{f}^{1-n} x_{f}}{E^{\prime}}\right)
$$

Where: $E^{\prime}$ is the plain strain in psi, Pa.s. (M. M. Rahman, (2002)), the power law $\left(E^{\prime}=\frac{1}{1-v^{2}}\right)$. parameters are correlated with fluid viscosity of fracturing fluid as:

Where: $n$ is flow behavior index (Dimensionless); $K$ is the consistency index $\left(P a \cdot \sec ^{\mathrm{n}}\right) ; v$ is in the Poisson's ratio and $\mu$ is in

$$
\begin{gathered}
n=0.1756 \times(\mu)^{-0.1233} \\
K=47.880 \times(0.5 \mu-0.0159)
\end{gathered}
$$




\section{Nguyen Huu Truong}

By using the shape factor of $\pi / 5$ for a 2D fracture width $\left(w_{a}\right)$ is given by $\pi / 5 \times w_{f}$ as PKN fracture geometry model, the average equation.

$$
w_{a}=\frac{\pi}{5} \times 9.15^{\frac{1}{2 n+2}} \times 3.98^{\frac{n}{2 n+2}}\left(\frac{1+(\pi-1) n}{n}\right)^{\frac{n}{2 n+2}} K^{\frac{1}{2 n+2}} \times\left(\frac{\left(q_{i} / 2\right)^{n} h_{f}^{1-n} x_{f}}{E^{\prime}}\right)
$$

Carter II solution formulates material balance in terms of injection rate to the well. At the injection time $t_{e}$, the injection rate enters one wing of the fracture area, the material balance presents the relationship between injection rate $(q)$ which is the total fracture volume with fluid volume losses to fractures. The material balance is presented as equation below.

$$
q=2 \int_{0}^{t} \frac{C_{L}}{\sqrt{t-\tau}} \times\left(\frac{d A}{d \tau}\right) d \tau+2 S_{p} \times \frac{d A}{d t}+w \times \frac{d A}{d t}+A \frac{d w}{d \tau}
$$

With an analytical solution for constant injection rate $(q)$, Carter solved the material

balance that gives the fracture area for two wings as:

$$
A(t)=\frac{w_{a}+2 S_{p}}{4 C_{L}^{2} \pi} \times q\left[\exp \left(\beta^{2}\right) \operatorname{erfc}(\beta)+\frac{2 \beta}{\sqrt{\pi}}-1\right]
$$

Hence fracture half-length with the fracture surface area $\left(A(t)=2 x_{f} h_{f}\right)$ is given by.

$$
A(t)=\frac{\left(w_{a}+2 S_{p}\right)}{4 \pi C_{L}^{2} h_{f}} \times \frac{q}{2}\left[\exp \left(\beta^{2}\right) \operatorname{erfc}(\beta)+\frac{2 \beta}{\sqrt{\pi}}-1\right]
$$

Where is $\beta=\frac{2 C_{L} \sqrt{\pi t}}{w_{a}+2 S_{p}}$

Equation (6) presents the fracture halflength during proppant slurry injection into the fractures and also describes the fracture propagation alongside the fractures with time, in which fracture half-length depends on several parameters as injection rate $(q)$, injection time $(t)$, leak-off coefficient $\left(C_{L}\right)$, spurt loss $\left(S_{p}\right)$, and fracture height $\left(h_{f}\right)$, the average fracture width $\left(w_{a}\right)$. From the close of equation (6) it can be easy to determine the valuable fracture half-length by using iterative method calculation. The PKN-C fracture geometry model can be seen the figure 1 .

\section{MATERIAL BALANCE}

Carter solved the material balance to account for leak-off coefficient, spurt loss, injection rate, injection time, and in terms of power law parameters as flow behavior index of $n$ and consistency index of $K$. Proppant slurry is pumped to the well under high pressure to produce fracture growth and fracture propagation. Therefore, the material balance is expressed as equation: $V_{i}=V_{f}+V_{l}$, where $V_{i}$ is the total fluid volume injected to the well, $V_{f}$ is the fracture volume that is required to stimulate reservoir, and $V_{l}$ is the total fluid volume losses to the fracture area in the reservoir. The fracture volume, $V_{f}$, is defined as two sides of the symmetric fracture of $V_{f}=2 x_{f} h_{f} w_{a}$, the fluid efficiency is defined by $V_{f} / V_{i}$. In 1986, Nolte proposed the relationship between the fluid volumes injected to the well with pad volume and also proposed a model for proppant schedule. At the injection time $t$, the injection rate is entered into two 
wings of the fractures with $q$, the material balance presented as the constant injection rate $q$ is the sum of the different leak-off flow rate and fracture volume as:

$$
q=2 \int_{0}^{t} \frac{C_{L}}{\sqrt{t-\tau}} \times\left(\frac{d A}{d \tau}\right) d \tau+2 S_{p} \times \frac{d A}{d t}+w \times \frac{d A}{d t}+A \frac{d w}{d \tau}
$$

The fluid efficiency of fractured well of the post fracture at the time $(t)$ is given by:

$$
\eta=\frac{w_{a} h_{f} x_{f}}{q t} \operatorname{or} \eta=\frac{w_{a} h_{f}\left(w_{a}+2 S_{p}\right)}{4 \pi C_{L}^{2} t} \times\left[\exp \left(\beta^{2}\right) \operatorname{erfc}(\beta)+\frac{2 \beta}{\sqrt{\pi}}-1\right]
$$

Where, $\beta=\frac{2 C_{L} \sqrt{\pi t}}{w_{a}+2 S_{p}}$ and $C_{L}$ is the leak-off coefficient in $\mathrm{ft} / \mathrm{min}^{0.5}, w_{a}$ is the average fracture width in the fractures in inch, $S_{p}$ is the spurt loss in the fractures in $\mathrm{gal} / \mathrm{ft}^{2}$.

\section{CENTRAL COMPOSITE DESIGN (CCD)}

The design of experiment (DOE) techniques is commonly used for process analysis and the models are usually the full factorial, partial factorial, and central composite rotatable designs. An effective alternative to the factorial design is the central composite design (CCD), which was originally developed by Box and Wilson and improved by Box and Hunter in 1957. The CCD was widely used as a three-level factorial design, requires much fewer tests than the full factorial design, and has been provided to be sufficient as describing the majority of steady state products of response. Currently, CCD is one of the most popular classes of design used for fitting second-order models. The total number of tests required for is $2^{k}+2 k+n_{o}$, including the standard $2^{k}$ factorial points with its origin at the center, $2 k$ points fixed axially at a distance, say $\beta\left(\beta=2^{\mathrm{k} / 4}\right)$, from the center to generate the quadratic terms, and replicate tests at the center $\left(n_{o}\right)$, where $k$ is the number of independent variables. These operating parameters of the variables are namely of injection rate of $X_{l}$, injection time of $X_{2}$, leak-off coefficient of $X_{3}$, and reservoir porosity of $X_{4}$, presenting the total number of tests that were required of the four variables of $2^{4}+(2.4)+3=27$ runs. In this experimental design, the center points were set at 3 and the replicates of zero value. Therefore, the three independent variables of the operating parameters of the CCD were shown in table 2 . The coded and actual levels of the dependent variables of each the experiment design in the matrix column is calculated in table 3 . From table 3 , the experiment of design is conducted for the obtaining the response.

\begin{tabular}{|c|c|c|c|c|}
\hline & & \multicolumn{3}{|c|}{ Coded variable level } \\
\hline & & Low & Center & High \\
\hline Variables & Symbol & -1 & 0 & 1 \\
\hline Injection rate, bpm & $\mathrm{X}_{1}$ & 18 & 19 & 20 \\
\hline Injection time, minutes & $\mathrm{X}_{2}$ & 60 & 90 & 120 \\
\hline Leak-off coefficient, $\mathrm{ft} / \mathrm{min}^{0.5}$ & $x_{3}$ & 0.003 & 0.005 & 0.007 \\
\hline Reservoir porosity, \% & $\mathrm{X}_{4}$ & 10 & 14 & 18 \\
\hline
\end{tabular}

Table 3. Four independent variables and their levels for Central Composite Design (CCD)

$\begin{array}{lllllll}\text { THE RECOMMENDION } & \text { ON } & \text { THE } & \text { FRACTURING } & \text { AND } & \text { RESERVOIR } \\ \text { RANGES OF } & \text { THE } & \text { OPERATING } & \text { POROSITY } & \text { OF } & \text { OLIGOCENE } \\ \text { PARAMETERS } & \text { OF } & \text { HYDRAULIC } & \text { RESERVOIR } & & \end{array}$


Table 4. Fracturing parameters

\begin{tabular}{|c|c|}
\hline Parameter & Value \\
\hline Fracture height, $\mathrm{h}_{\mathrm{f}}, \mathrm{ft}$. & 72 \\
\hline Sandstone Poisson's ratio & 0.25 \\
\hline Leak-off coefficient, $\mathrm{ft} / \mathrm{min}^{0.5}$ & 0.003 to 0.007 \\
\hline Young's modulus, psi & $5.00 \times 10^{6}$ \\
\hline Injection rate, bpm & 18 to 22 \\
\hline Injection time, $\min$ & 60 to 120 \\
\hline Spurt loss, in & 0 \\
\hline $\begin{array}{l}\text { End of job (EOJ) proppant concentration, } \\
\text { ppg }\end{array}$ & 8 \\
\hline Flow behavior index, $\mathrm{n}$ & 0.55 \\
\hline Consistency index, $K$, lbf. $. \mathrm{s}^{\mathrm{n}} / \mathrm{ft}^{2}$ & 0.04 \\
\hline \multicolumn{2}{|c|}{$\begin{array}{l}\text { Fracturing fluid type: Cross-linked of } 30 \text { pptg HPG } \\
\text { Persulfate with } 8 \text { pptg breaker } \mathrm{Na}_{2} \mathrm{~S}_{2} \mathrm{O}_{8}\end{array}$} \\
\hline
\end{tabular}

Interestingly, the hydraulic fracturing treatment in the field can be divided into two types of parameters as operating parameters of hydraulic fracturing such as injection rate, injection time, and leak-off coefficient at which these parameters are controlled from the surface and facilities and the rest of parameters cannot be controlled such as rock properties, young modulus, poisson's ratio, geological structural, reservoir porosity, reservoir permeability, fracture closure pressure and the stress regime of the fracture of normal fault stress regime, strike slip regime, reverse faulting stress regime. In this article, the author has presented the effect of operating parameters of hydraulic fracturing and reservoir porosity on economic performance. Accordingly, the normal faulting stress regime of the reservoir with the minimum horizontal stress as closure pressure is up to $7,700 \mathrm{psi}$. In this research, the recommended operating parameter is based on the field experience offshore Vietnam. The injection rate is in the range from $18 \mathrm{bpm}$ to $22 \mathrm{bpm}$, injection time $i$ in the range of 60 minutes to 120 minutes, and the leak-off coefficient $i$ in the range of $0.003 \mathrm{ft} / \mathrm{min}^{0.5}$ to $0.007 \mathrm{ft} / \mathrm{min}^{0.5}$ for designing the leak-off coefficient in Oligocene sandstone reservoir, and the reservoir porosity ranges from $10 \%$ to $18 \%$. One of the important operating parameters of hydraulic fracturing is the leakoff coefficient at which the leak-off coefficient had more effect on the fracture geometry of the fracture half-length and fracture width as well as the economic performance. Currently total leak-off coefficient is controlled by three mechanisms of rock compressibility, invaded zone, and wall building effect. In the three mechanisms, only one parameter can controll filtration viscosity of fracturing fluid system. Usually the increasing fracturing fluid viscosity as high polymer concentration of fracturing fluid leads to high fracturing fluid density. It can decrease the wall building effect as decrease in the total leak-off coefficient. In this research, the author proposed the fracturing fluid parameters and fluid properties as in table 4.

The model for overall leak-off coefficient was presented by Williams, (1970) and Williams et al., (1979) [3, 4] as:

$$
C_{1}=\frac{-\frac{1}{C_{c}}+\sqrt{\frac{1}{C_{c}^{2}}+4\left(\frac{1}{C_{v}^{2}}+\frac{1}{C_{w}^{2}}\right)}}{2\left(\frac{1}{C_{v}^{2}}+\frac{1}{C_{w}^{2}}\right)}
$$

That formula is modified as equation below:

$$
\frac{2}{C_{1}}=\frac{1}{C_{c}}+\sqrt{\frac{1}{C_{c}^{2}}+4\left(\frac{1}{C_{v}^{2}}+\frac{1}{C_{w}^{2}}\right)}
$$

In which, $C_{c}$ is the total compressibility fluid loss leak-off in reservoir conditions in $\mathrm{ft} / \mathrm{min}^{0.5}$ that calculated by the equation below:

$$
C_{c}=S_{o} C_{o}+S_{w} c_{w}+S_{g} C_{g}+C_{r}
$$

In which, $S_{o}$ is the oil saturation in $\% ; C_{o}$ is the compressibility of oil in $\mathrm{psi}^{-1} ; S_{w}$ is the water saturation in \%; $c_{w}$ is the compressibility of the water in $\mathrm{psi}^{-1} ; S_{g}$ is the gas saturation in $\% ; C_{g}$ is the compressibility of gas in $\mathrm{psi}^{-1} ; C_{r}$ is the compressibility of the rock in $\mathrm{psi}^{-1} ; C_{v}$ is the viscous fluid loss coefficient due to the filtration in $\mathrm{ft} / \mathrm{min}^{0.5} ; C_{w}$ is the wall building of fluid loss coefficient in $\mathrm{ft} / \mathrm{min}^{0.5} ; C_{t}$ is the total compressibility in $\mathrm{psi}^{-1} ; \quad C_{c}$ is leak-off coefficient due to total compressibility in $\mathrm{ft} / \mathrm{min}^{0.5} ; C_{l}$ is the leak-off coefficient in $\mathrm{ft} / \min ^{0.5}$.

\section{FRACTURE CONDUCTIVITY}




\section{Effect of operating parameters of hydraulic...}

The value of fracture conductivity that is usually measured from laboratory data (API standard) based on proppant type, proppant size, proppant shape, proppant damage factor, proppant permeability, proppant porosity under closure pressure is very important to predict the oil production. The API standard for a test such as data to measure linear flow through the proppant pack between steel plates under specific pressure is applied to it. Then the standard API is usually tested at a proppant concentration of $2 \mathrm{lb} / \mathrm{ft}^{2}$. This theory most published data measured by API test (Smith, (1997)).

If the proppant permeability under closure pressure known for the each proppant type was selected, then in-situ fracture conductivity can be evaluated by.

$$
\text { Fracture conductivity }=k_{f} \times w_{p}
$$

In terms of simulation fracture conductivity, if the closure pressure, proppant fracture concentration in $\left(\mathrm{lb} / \mathrm{ft}^{2}\right)$ is known by using Mfrac software, it can also calculate a fracture conductivity, proppant permeability, proppant porosity under closure pressure.

\section{DIMENSIONLESS FRACTURE CON- DUCTIVITY}

The dimensionless fracture conductivity, $\mathrm{F}_{\mathrm{CD}}$, can be defined as (Cinco-Ley et al., (1978)) and given by:

$$
F_{C D}=\frac{k_{f} \times w_{p}}{k \times x_{f}}
$$

In which: $k$ is the reservoir permeability in $\mathrm{mD}$; $x_{f}$ is the fracture length of fractured well in $\mathrm{ft}$;; $k_{f}$ is the proppant permeability under closure pressure applied on the proppant laden; $w_{p}$ is the propped fracture width at the end of the job.

\section{Transient production flow regime}

Based on the constant bottom hole pressure situation, the oil production from fractured well in transient flow regime can be calculated by (Economides et al., (1994)).

$$
p_{i}-p_{w f}=\frac{162.6 q_{o} B \mu}{k h}\left(\log t+\log \left(\frac{k}{\phi \mu c_{t} r_{w}^{\prime 2}}\right)+s_{f}-3.23\right)
$$

In which, $r_{w}^{\prime}$ is the effective wellbore radius and given by: $r_{w}^{\prime}=r_{w} e_{f}^{-s}, s_{f}$ is pseudo-skin is calculated by the relationship (Valko's et al., 1997): $s_{f}=F-\ln \left(\frac{x_{f}}{r_{w}}\right)$, where $x_{f}$ is the fracture half-length, and $r_{w}$ is the wellbore radius. The $F$ factor can be calculated by:

$$
F=\frac{1.65-0.328 u+0.116 u^{2}}{1+0.18 u+0.64 u^{2}+0.005 u^{3}}
$$

Where $u=\ln \left(F_{C D}\right)$ and $F_{C D}$ is the dimensionless fracture conductivity which is calculated by $F_{C D}=\frac{k_{f} w_{p}}{k x_{f}}$, also $F_{C D}$ is related to proppant number which is along the penetration ratio $\left(l_{x}=2 x_{f} / x_{e}\right)$ and $k_{f} w_{p}$ is the fracture conductivity which can be calculated by laboratory experiment or conductivity simulation when knowing a propant fracture concentration in $\mathrm{lb} / \mathrm{ft}^{2}$ inside fracture under closure pressure applied on the proppant laden. Basically, the proppant number is defined by (Economides et al., 2001).

$$
N_{\text {propp }}=\left(\frac{2 k_{f}}{k_{\text {res }}}\right) \times \frac{V_{\text {prop }}}{V_{\text {res }}}
$$

Where $k_{f}$ is the effective proppant pack permeability; $\mathrm{k}$ is the reservoir permeability; $V_{\text {prop }}$ is the propped volume in the pay zone (two wings, including void space between the proppant grains); $V_{\text {res }}$ is the drainage volume. The transient production period is often short time oil production.

\section{NET PRESENT VALUE (NPV) MODEL}

In 1986, Veatch presented a comprehensive procedure of the various techniques. In 1987, 
Meng and Brown proposed the net present value $(N P V)$ as an approximate treatment optimization approach. In 1988, Balen et al., presented a series of the parametric studies and the components of the NPV calculation. Net present value is defined as the revenue from the production forecast for the fractured well less the production forecast for the same reservoir with unstimulated well and the total cost of treatment in current dollars. In this research, the net present value of the future revenue can be calculated by the following equation:

$$
\begin{aligned}
N P V & =\sum_{j=1}^{N} \frac{\left(V_{F}\right)_{j}}{(1+i)^{j}}-\sum_{j=1}^{N} \frac{\left(V_{o}\right)_{j}}{(1+i)^{j}}-C_{t r} \\
C_{t r} & =C_{p r}+C_{t f l}+C_{p u}+F C
\end{aligned}
$$

In order to calculate total fluid cost, Rahman et al., 2003 presented to calculate total fluid volume without proppant as the following equation:

$$
V_{t f l}=V_{p a d}+V_{f l}
$$

To compute the fracturing fluid volume of proppant slurry stage, then the amount of fracturing fluid volume is only mixed with dry proppant in the slurry stage and given by:

$$
V_{f l}=\frac{W_{p r}}{\bar{P}_{c}}
$$

In which, $\bar{P}_{c}=\eta P_{c}$.

Where: $C_{t r}$ is the total treatment cost in $\$ ; C_{p r}$ is the total proppant cost in $\$ ; C_{t f l}$ is the total fluid cost in $\$ ; C_{p u}$ is the total pumping horse power cost in $\$ ; C_{F}$ is the total fixed cost in $\$ ; \bar{P}_{c}$ is the average proppant concentration in ppg; $P_{c}$ is the end of job (EOJ) proppant concentration, finally $\eta$ is the fluid efficiency; $W_{p r}$ is the total proppant mass in lbs; $V_{\text {pad }}$ is the pad volume in gallons; $\mathrm{V}_{\mathrm{fl}}$ is the total fluid loss in gallons without proppant.

Where: $N P V$ is the net present value in a fractured well; $N$ is the number of periods; $V_{F}$ is the fracture value production revenue of a stimulated case reservoir; $V_{o}$ is the fracture value production revenue of an unstimulated case reservoir; $i$ is the discount rate in $\%$.

\section{OLIGOCENE RESERVOIR DATA}

The well was drilled with appraisal oil well production reserves in the Pre-Tertiary fractured basement reservoir and the Oligocene sandstone reservoir of the field in Cuu Long basin, offshore Vietnam. In this study, the reservoir data is gathered from the Lower Oligocene reservoir with the reservoir depth of $3,400 \mathrm{~m}$ to $4,000 \mathrm{~m}$ and the reservoir data presented in table 4 .

\section{DESIGN OF EXPERIMENT USING CENTRAL COMPOSITE DESIGN FOR OPERATING PARAMETERS OF HYDRAULIC FRACTURING AND ECONOMIC MODEL}

The injection rate of hydraulic fracturing for Oligocene reservoir follows the field experience at which the injection rate was considered in the range from $18 \mathrm{bpm}$ to $22 \mathrm{bpm}$ of the variable $X_{1}$ (Rahman, M. M., (2008)). Usually, the injection rate has more effect on the fracture half-length as the injection rate is increased, the fracture half-length is increased, the fracture conductivity and the net present value (NPV) are also increased. Accordingly, when the injection rate decreases, the fracture half-length decreases, the fracture conductivity and the net present value of course decrease (Haiqing $\mathrm{Yu}$ and Rahman, M. M., SPE 152439). Similarly, the effect of injection time on the fracture half-length was presented by Haiqing Yu and Rahman, M. M., SPE 152439. The research presented that the increase in the injection time leads to the increase in fracture half-length. Whereas, the decrease in the injection time leads to decrease in the fracture half-length because the injection time is directly proportional to fracture half-length (Economides et al.,). Thus, the injection time is a very important variable which has much affect on the fracture half-length as well as the net present value $(N P V)$. Many studies previously confirmed that injection time is directly proportional to net present value with the limited injection time following the range of field experience. Oftentimes, the injection 


\section{Effect of operating parameters of hydraulic...}

time of hydraulic fracturing stimulation for tight oil reservoir is considered as 60 minutes to 120 minutes of the variable $X_{2}$ (Rahman, M. M., (2008)). The effect of the leak-off coefficient on the net present value was presented by (Economides et al., (1993)); the presentation performed that the total leak-off coefficient increases, the net present value decreases because the more leak-off coefficient usually leads to more fluid volume loss and narrow fracture dimension as poor fracture conductivity of the post fracture. Thus, the high leak-off coefficient as low polymer concentration of the hydraulic fracturing reduces oil production rate in the post fracture. Whereas, the low leak-off coefficient of high polymer concentration of fracturing fluid leads to more fracture dimensions during fracturing of longer fracture length and wider fracture width as more fracture conductivity. Thus, low leak-off coefficient increases the net present value. Usually, the total leak-off coefficient is directly proportional to the main polymer concentration and fluid additive. In this study, hydraulic fracturing for the field of tight oil reservoir with the leak-off coefficient is considered in the range of $0.002 \mathrm{ft} / \mathrm{min}^{0.5}$ to $0.004 \mathrm{ft} / \mathrm{min}^{0.5}$ of the variable $X_{3}$ as shown in the table 2. And the porosity is the important parameter in order to evaluate the oil production rate of the reservoir at that time. Furthermore, oil production rate is gradually declined in 10 years because the reservoir porosity is gradually reduced from $18 \%$ to $10 \%$. Therefore, the cumulative oil production has been reduced due to the reduce in reservoir porosity.

Table 5. Independent variables and results from post-production with simulation observed by Central Composite Design (CCD)

\begin{tabular}{|c|c|c|c|c|c|c|c|c|c|c|c|}
\hline \multirow[b]{2}{*}{ Run } & \multicolumn{4}{|c|}{$\begin{array}{l}\text { Coded level of the } \\
\text { variables }\end{array}$} & \multicolumn{4}{|c|}{ Actual level of variables } & \multicolumn{3}{|c|}{$\begin{array}{c}\text { Response (Simulation } \\
\text { and observed) }\end{array}$} \\
\hline & $X_{1}$ & $x_{2}$ & $x_{3}$ & $X_{4}$ & $\begin{array}{l}\text { Injection } \\
\text { rate, bpm }\end{array}$ & $\begin{array}{l}\text { Injection } \\
\text { time, } \min \end{array}$ & $\begin{array}{l}\text { Leak-off, } \\
\mathrm{ft} / \min ^{0.5}\end{array}$ & Por, \% & $\begin{array}{l}\text { Fracture } \\
\text { half- } \\
\text { length, } \mathrm{ft}\end{array}$ & $\begin{array}{l}\text { Cumulative } \\
\text { production, } \\
\text { Mbbls }\end{array}$ & $\mathrm{NPV}, \$ \mathrm{~mm}$ \\
\hline 1 & -1 & -1 & -1 & -1 & 18 & 60 & 0.003 & 10 & 499.8 & 459.531 & 11.9 \\
\hline 2 & 1 & -1 & -1 & -1 & 22 & 60 & 0.003 & 10 & 602.7 & 465.741 & 12.2 \\
\hline 3 & -1 & 1 & -1 & -1 & 18 & 120 & 0.003 & 10 & 727.2 & 469.65 & 12.2 \\
\hline 4 & 1 & 1 & -1 & -1 & 22 & 120 & 0.003 & 10 & 879.0 & 473.96 & 12.3 \\
\hline 5 & -1 & -1 & 1 & -1 & 18 & 60 & 0.007 & 10 & 235.3 & 428.942 & 10.7 \\
\hline 6 & 1 & -1 & 1 & -1 & 22 & 60 & 0.007 & 10 & 286.2 & 439.364 & 11.1 \\
\hline 7 & -1 & 1 & 1 & -1 & 18 & 120 & 0.007 & 10 & 336.1 & 445.069 & 11.3 \\
\hline 8 & 1 & 1 & 1 & -1 & 22 & 120 & 0.007 & 10 & 409.2 & 453.612 & 11.6 \\
\hline 9 & -1 & -1 & -1 & 1 & 18 & 60 & 0.003 & 18 & 499.8 & 508.662 & 13.9 \\
\hline 10 & 1 & -1 & -1 & 1 & 22 & 60 & 0.003 & 18 & 602.7 & 516.194 & 14.2 \\
\hline 11 & -1 & 1 & -1 & 1 & 18 & 120 & 0.003 & 18 & 727.2 & 520.938 & 14.3 \\
\hline 12 & 1 & 1 & -1 & 1 & 22 & 120 & 0.003 & 18 & 879.0 & 526.175 & 14.5 \\
\hline 13 & -1 & -1 & 1 & 1 & 18 & 60 & 0.007 & 18 & 235.2 & 471.731 & 12.5 \\
\hline 14 & 1 & -1 & 1 & 1 & 22 & 60 & 0.007 & 18 & 286.1 & 484.28 & 12.9 \\
\hline 15 & -1 & 1 & 1 & 1 & 18 & 120 & 0.007 & 18 & 336.1 & 491.165 & 13.1 \\
\hline 16 & 1 & 1 & 1 & 1 & 22 & 120 & 0.007 & 18 & 409.2 & 501.494 & 13.5 \\
\hline 17 & -1 & 0 & 0 & 0 & 18 & 90 & 0.005 & 14 & 396.6 & 477.616 & 12.6 \\
\hline 18 & 1 & 0 & 0 & 0 & 22 & 90 & 0.005 & 14 & 481.5 & 486.021 & 12.9 \\
\hline 19 & 0 & -1 & 0 & 0 & 20 & 60 & 0.005 & 14 & 355.0 & 473.531 & 12.5 \\
\hline 20 & 0 & 1 & 0 & 0 & 20 & 120 & 0.005 & 14 & 510.3 & 487.58 & 13 \\
\hline 21 & 0 & 0 & -1 & 0 & 20 & 90 & 0.003 & 14 & 687.8 & 496.726 & 13.4 \\
\hline 22 & 0 & 0 & 1 & 0 & 20 & 90 & 0.007 & 14 & 321.5 & 468.992 & 12.3 \\
\hline 23 & 0 & 0 & 0 & -1 & 20 & 90 & 0.005 & 10 & 439.1 & 455.663 & 11.7 \\
\hline 24 & 0 & 0 & 0 & 1 & 20 & 90 & 0.005 & 18 & 439.1 & 503.97 & 13.7 \\
\hline 25 & 0 & 0 & 0 & 0 & 20 & 90 & 0.005 & 14 & 439.1 & 482.183 & 12.8 \\
\hline 26 & 0 & 0 & 0 & 0 & 20 & 90 & 0.005 & 14 & 439.1 & 482.183 & 12.8 \\
\hline 27 & 0 & 0 & 0 & 0 & 20 & 90 & 0.005 & 14 & 439.1 & 482.183 & 12.8 \\
\hline
\end{tabular}




\section{Nguyen Huu Truong}

The reasonable experiment design of the central composite design is to investigate the effects of three operating parameters of hydraulic fracturing and one parameter from the reservoir porosity on the production performance to the net present value of the response. These operating parameters of the variables, namely injection rate, $X_{1}$, injection time, $X_{2}$, leak-off coefficient, $X_{3}$, and reservoir porosity, $X_{4}$, have presented the total number of test that was required of the four variables of
$2^{4}+(2.4)+4=27$. In this experiment design, the center point was set of 3 and the replicates of zero value. Therefore, the three independent variables of the operating parameters of the CCD were shown in table 5. The coded and actual levels of the dependent variables of each the experiment design in the matrix column is calculated in table 6 . From table 6, the experiment of design is conducted for obtaining the response.

Table 6. ANOVA analysis

\begin{tabular}{|c|c|c|c|c|c|c|}
\hline NPV & DF & SS & MS & $F$ & $\mathbf{P}$ & SD \\
\hline Total & 27 & $4.37401 \times 10^{15}$ & $1.62 \times 10^{14}$ & & & \\
\hline Constant & 1 & $4.34975 \times 10^{15}$ & $4.34975 \times 10^{15}$ & & & \\
\hline Total connected & 26 & $2.42588 \times 10^{13}$ & $9.3303 \times 10^{11}$ & & & 965935 \\
\hline Regression & 14 & $2.42476 \times 10^{13}$ & $1.73197 \times 10^{12}$ & 1865.35 & 0.000 & $1.31604 \times 10^{6}$ \\
\hline Residual & 12 & $1.11419 \times 10^{10}$ & $9.28496 \times 10^{8}$ & & & 30471.2 \\
\hline Lack-off fit & 10 & $1.11419 \times 10^{10}$ & $1.11419 \times 10^{9}$ & $1.386 \times 10^{11}$ & & 33379.6 \\
\hline Pure error & 2 & 0.0160732 & 0.00803661 & & & 0.0896472 \\
\hline $\begin{array}{l}\mathrm{N}=27 \\
\mathrm{DF}=12\end{array}$ & $\begin{array}{l}\mathrm{Q}^{2}=0.997 \\
\mathrm{R}^{2}=0.99 \\
\mathrm{R}_{\text {Adj }}^{2}=0.98\end{array}$ & & $\begin{array}{l}\text { Cond.no. }=6.6122 \\
\text { Y-miss }=0 \\
\text { RSD }=30471.228\end{array}$ & & & \\
\hline
\end{tabular}

The net present value model for 10 years of oil production of each run with the average reservoir pressure is of 4,990 psi and bottom hole flowing pressure is set at 3,500 psi. Table 3 summarized the result of the response in order to analyze the fractured well of the post fracture production. Therefore, the independent variables are correlated with the surface response. From the response of the net present value and the result of oil recovery, the operating engineers can control the proper operating parameters of hydraulic fracturing. It can observe the maximum net present value at which the operating parameters of hydraulic fracturing were determined.

The net present value model is to estimate the economic performance based on the field of drilling and production contractor offshore Vietnam. A simple cash flow model in an Excel spreadsheet calculated from the yearly income includes the depreciation regarding a typical contractor fiscal regime in Vietnam. These simulator cases run over 10 years of each case, and the results include the cumulative oil production of the fractured well, injection time, leak-off coefficient of hydraulic fracturing, the amount of proppant used, the amount of the used fracturing fluid of the each run has been gathered. Thus, these input parameters for the net present value model consist of the average oil price of $60 \$ / \mathrm{bbl}$, fracturing fluid price per gallon of 1 \$/gallon, proppant price of $1 \$ / \mathrm{lb}$, hydraulic horse power price of $40 \$ / \mathrm{hhp}$, fixed price of $30,000 \$$ and the discount rate of $10 \%$ of the Contractor Field Vietnam (2015). In the pressure model, the surface treating pressure is set up to 6,000 psi which is very important parameter in order to estimate the pump horse power requirement.

\section{RESULTS AND ANALYSIS}

Response surface method is more convenient compare to traditional single parameter in order to find optimization of the response value. In this research, there are a total of 27 run cases to find where the point of these variables optimized each parameter in the current design of experiment. Table 5 has shown the result of the experimental conditions 
and the response of the net present value of each run case, and the amount of oil recovery of each run case in 10 years of oil production scenario according to the central composite design. In table 5 , it is easy to observe where the point has been maximized. This is the maximum net present value at run case of 12 under operating parameters of hydraulic fracturing of $22 \mathrm{bpm}$ of injection rate, 120 minutes of injection time, and $0.003 \mathrm{ft} / \mathrm{min}^{0.5}$ of leak-off coefficient. Especially on the run 12, the maximum oil recovery where reservoir porosity reaches $18 \%$. By the response surface, the relationship between these variables and the response of the net present value has been correlated as:

$$
\begin{aligned}
N P V= & 12.8025+0.15 X_{1}+0.216667 X_{2}-0.55 X_{3}+0.98 X_{4}-0.0537043 X_{1}^{2} \\
& -0.0537028 X_{2}^{2}+0.0190021 X_{3}^{2}+0.103704 X_{4}^{2}-0.025 X_{1} X_{2}+0.0375007 X_{1} X_{3} \\
& +0.0125 X_{1} X_{4}+0.075 X_{2} X_{3}+0.025 X_{2} X_{4}-0.0625 X_{3} X_{4}
\end{aligned}
$$

Accordingly, the results of the analysis of these variances in table 2 have shown the ANOVA of the quadratic regression model. From the ANOVA table, the determination coefficient of $\mathrm{R}^{2}=0.99$ indicated that only a few percent of the total variations were not explained by the net present value model (20). Meanwhile, the value of the adjusted determination coefficient (Adjusted coefficient $\left.\mathrm{R}^{2}=0.98\right)$ according to the net present value model (20) was highly significant.

\section{MAIN EFFECT PLOTS ON THE NET PRESENT VALUE}

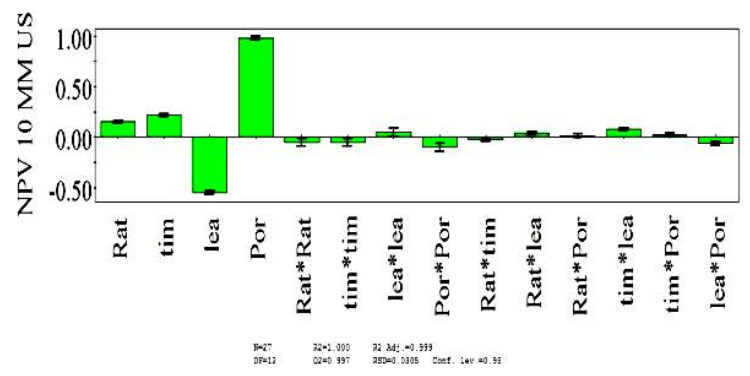

Fig. 2. The effects of these variables on the net present value (NPV)

The main effect plot is appropriate in order to analyze data based on the design of experiments. The expected main parameters affect the net present value of the response. Fig. 1 has shown the effect plot of the variables on the net present value. Accordingly, the figure has been divided into two regions. The first region presents these variables of the negative factors such as $X_{3}, X_{1} . X_{1}, X_{2} \cdot X_{2}, X_{4} \cdot X_{4}$,
$X_{1} . X_{2}, X_{3} . X_{4}$ that decrease the net present value. Especially, one of the big variable effects on the net present value is the negative factor of leak-off coefficient. This explains why during hydraulic fracturing, more leak-off coefficient as well as larger volume loss into the reservoir leads to shorter fracture half-length. Therefore, the result of fractures is low fracture conductivity as low oil recovery. In the second region, these factors are above zero, which present positive value such as reservoir porosity, $X_{4}$, injection time, $X_{2}$, injection rate, $X_{1}$, injection time $\times$ leak-off coefficient, $X_{2} . X_{3}$, injection rate $\times$ reservoir porosity, $X_{1} . X_{4}$, injection time $\times$ leak-off coefficient, $X_{2} . X_{3}$, injection time $\times$ reservoir porosity, $X_{2} . X_{4}$. Accordingly, the higher reservoir porosity of course leads to high net present value due to more reservoir porosity of high oil recovery. Fig. 2 presents the actual net present value and predicts net present value versus data number. The predicted data approximates the actual data. Thus, the model is highly significant. Through fig. 2, the reservoir porosity much affects the net present value. Accordingly, the high leak-off coefficient decreases the net present value because the leak-off coefficient is inversely proportional to the fracture halflength. This is because the high leak-off coefficient during hydraulic fracturing makes more fluid volume loss into the fracture face area among the fractures, which leads to reduce in the fracture volume, shorter fracture halflength and low fracture conductivity. The results are low oil recovery of low net present 
value. Fig. 3 presents the actual net present value and predicts value versus the data number. Through the model it is highly significant with the coefficient confident factor of R-square reaching $99 \%$. The fig. 4, 5, 6, 7 present the single parameters as injection rate, injection time, leak-off coefficient, and reservoir porosity that effect the net present value. Especially in fig. 6, the increased leakoff coefficient leads the rapid increase in the net present, compared to other figures.

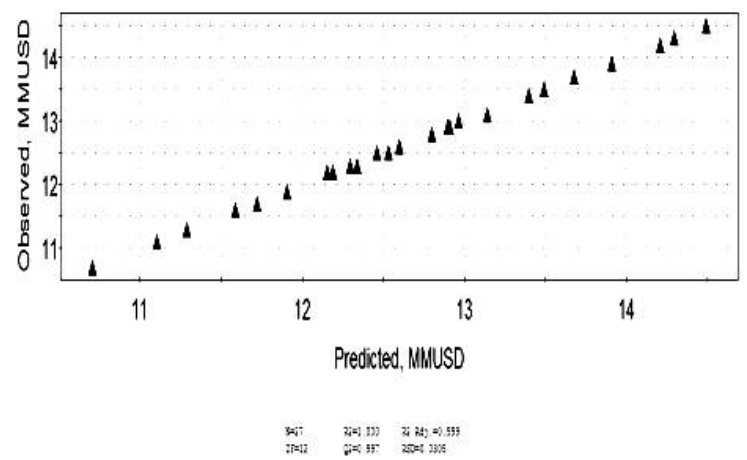

Fig. 3. The actual net present value (NPV) and predicted net present value (NPV) versus data number

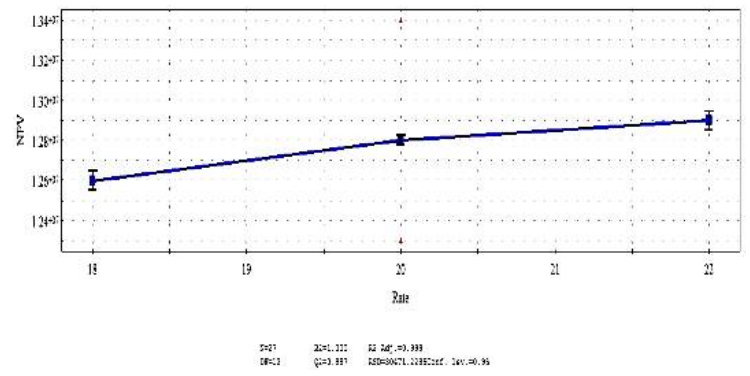

Fig. 4. The effect of the injection rate on NPV

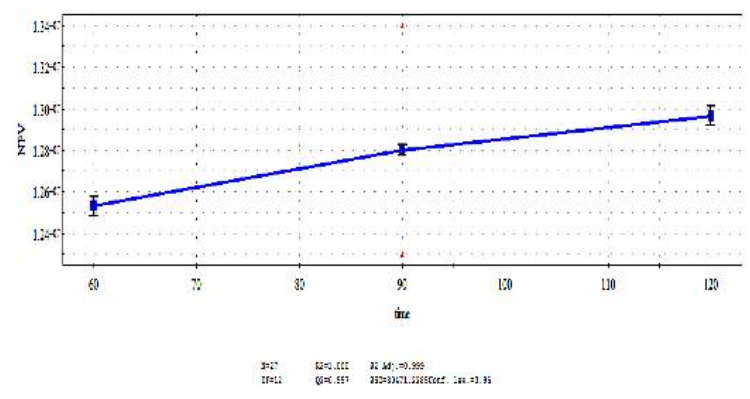

Fig. 5. The effect of the injection time on NPV

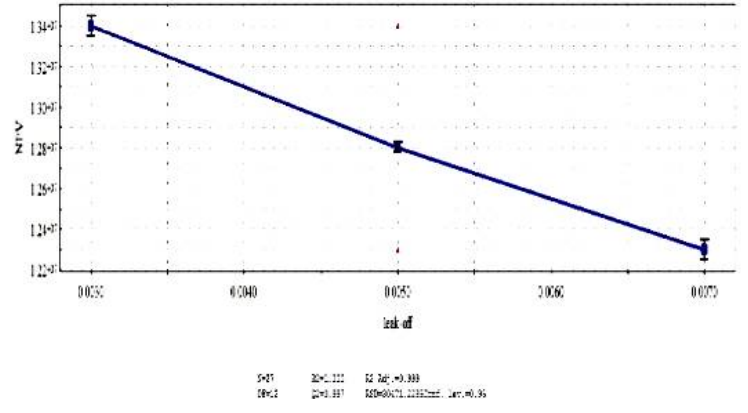

Fig. 6. The effect of leak-off coefficient on NPV

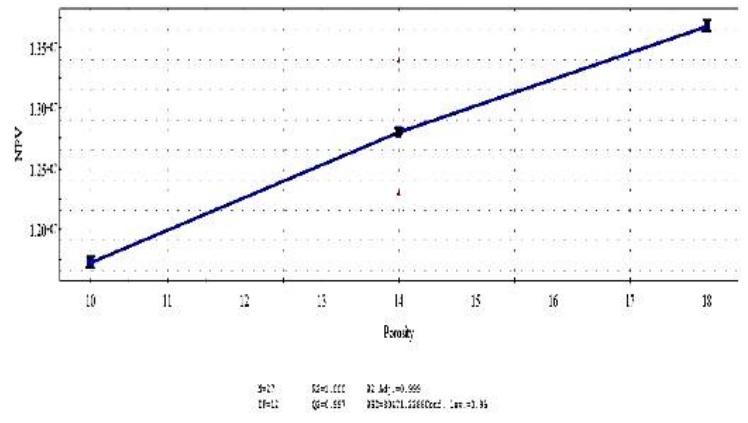

Fig. 7. The effect of reservoir porosity on NPV

\section{CONCLUSIONS}

Through this work there are a total number of 27 run cases by using the central composite design (CCD) which is designed for 4 variables such as injection rate, injection time, leak-off coefficient and reservoir porosity in this field with the response of the net present value for production recovery of 10 years. On the other hand, the 2D PKN-C model is combined with the unified fracture design based on the given proppant mass of each run case. The author could summarize the main points as follows:

The main single parameter as leak-off coefficient much affects the decrease in the net present value in the post hydraulic fractured well in 10 years.

The main single operating parameters such as injection rate, injection time, and reservoir porosity are directly proportional to the net present value.

The reservoir porosity strongly affects on the net present value compared to the other variables. 
The main effect plots and interaction effect plots presente the effects on the net present value.

Acknowledgement: The author in this article would like to thank University of PetroVietnam who has sponsored me to complete this study.

\section{REFERENCES}

1. Economides, M., Oligney, R., and Valkó, P., 2002. Unified fracture design: bridging the gap between theory and practice. Orsa Press.

2. Valko, P., and Economides, M. J., 1995. Hydraulic fracture mechanics (Vol. 318). Chichester: Wiley.

3. Williams, B. B., 1970. Fluid loss from hydraulically induced fractures. Journal of Petroleum Technology, 22(7), 882-888.

4. Williams, B. B., Gidley, J. L., and Schechter, R. S., 1979. Acidizing fundamentals. Henry L. Doherty Memorial Fund of AIME, Society of Petroleum Engineers of AIME.

5. Truong, N. H., Bae, W., and Nhan, H. T., 2016. Integrated Model Development for Tight Oil Sands Reservoir with 2D Fracture Geometry and Reviewed Sensitivity Analysis of Hydraulic Fracturing. Research Journal of Applied Sciences, Engineering and Technology, 12(4), 375-385.
6. Nguyen, D. H., and Bae, W., 2013. Design Optimization of Hydraulic Fracturing for Oligocene Reservoir in Offshore Vietnam. In IPTC 2013: International Petroleum Technology Conference.

7. Meyer (year?). Fracturing Simulation. Mfrac Software.

8. Balen, R. M., Mens, H. Z., and Economides, M. J., 1988. Applications of the net present value (NPV) in the optimization of hydraulic fractures. In SPE Eastern Regional Meeting. Society of Petroleum Engineers.

9. Marongiu-Porcu, M., Economides, M. J., and Holditch, S. A., 2008. Economic and physical optimization of hydraulic fracturing. In SPE International Symposium and Exhibition on Formation Damage Control. Society of Petroleum Engineers.

10. Yu, H., and Rahman, M. M., 2012. Pinpoint multistage fracturing of tight gas sands: An integrated model with constraints. In SPE Middle East Unconventional Gas Conference and Exhibition. Society of Petroleum Engineers.

11. Myers, R. H., Montgomery, D. C., and Anderson-Cook, C. M., 2016. Response surface methodology: process and product optimization using designed experiments. John Wiley \& Sons. 